\title{
CLIO
HISTOIRE, FEMMES ET SOCIÉTÉS
}

Clio, histoire, femmes et sociétés est une revue francophone d'histoire des femmes nouvellement créée par neuf historiennes universitaires :

Christine Bard (université d'Angers), Agnès Fine (université de Toulouse), Gabrielle Houbre (université Paris 7-Denis Diderot), Christiane Klapisch-Zuber (E.H.E.S.S.), Claudine Leduc (université de Toulouse), Catherine Marand-Fouquet (université d'Aix-Marseille), Florence Rochefort (université Paris 7), Françoise Thébaud (université de Lyon 2) et Michelle ZancariniFournel (université Paris 8).

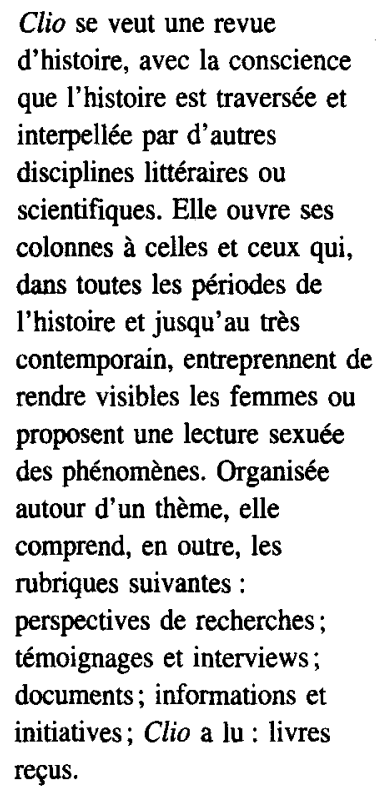

Les trois premiers numéros qui comprendront aussi de nombreuses rubriques informatives portent sur:

\section{Résistances et Libérations}

(France 1940-1945),

responsable Françoise Thébaud, université de Lyon 2

Femmes et religions

responsables Agnès Fine et Claudine Leduc, université de Toulouse 2

Femmes et syndicalisme responsable Michelle Zancarini-Fournel, université de Paris 8

Contact : Presses universitaires du Mirail, 56 rue du Taur, 31000 Toulouse, tél. : 612258 31, fax : 61218420 . 